\title{
Tracing two apprentices' Trajectories Toward Adaptive Professional Expertise in Fingerprint Examination
}

\section{Mustonen, Virpi}

2015-07

Mustonen , V \& Hakkarainen , K 2015 , ' Tracing two apprentices' Trajectories Toward Adaptive Professional Expertise in Fingerprint Examination ', Vocations and Learning , vol. 8 , no. 2 , pp. 185-211 . https://doi.org/10.1007/s12186-015-9130-7

http://hdl.handle.net/10138/314702

https://doi.org/10.1007/s12186-015-9130-7

acceptedVersion

Downloaded from Helda, University of Helsinki institutional repository.

This is an electronic reprint of the original article.

This reprint may differ from the original in pagination and typographic detail.

Please cite the original version. 
A draft of publication Mustonen V. \& Hakkarainen, K. (2015). Tracing two apprentices' trajectories toward adaptive professional expertise in fingerprint examination. Vocations and Education. DOI: 10.1007/s12186015-9130-7.

\title{
Tracing two apprentices' trajectories toward adaptive professional expertise in fingerprint examination
}

Virpi Mustonen, National Bureau of Investigation, P.O. Box 285, FI-01301 Vantaa, Finland. virpi.mustonen@poliisi.fi, tel. +35840 7016666.

Kai Hakkarainen, University of Helsinki, Faculty of Behavioural Sciences, Siltavuorenpenger 5 A, P.O. Box 9, FI-00014 University of Helsinki Finland. kai.hakkarainen@ helsinki.fi, tel. +358 50 4129572.

\begin{abstract}
The purpose of this study is to analyse the development of two apprentices' adaptive expertise in fingerprint examination across a two-year training program. The apprentices were selected from a large number of candidates to be trained at the Forensic Laboratory of the Finnish National Bureau of Investigation. The problem addressed was how the newcomers' professional vision needed for examining fingerprints developed, what kinds of agentic efforts for improving performance did they engage in when analysing successively more challenging fingerprints, and how did they themselves reflect on their developing professional performance. The study relied on multiple bodies of data consisting of a large number of fingerprints examined by the apprentices, repeated interviews, and their extensive learning diaries. The analysis revealed various challenges and obstacles of acquiring the professional vision and skills of fingerprint examination, such as identifying relevant minutiae in poor-quality fingerprints, carrying out searches through the Automatic Fingerprint Identification System (AFIS), and interpreting results. Although the apprentices cultivated self-reflective competencies, the professional practices appropriated also mirrored some of the maladaptive working habits of the experienced examiners with whom they were working. Through the training process, both of the apprentices gained professional competencies comparable with those of experienced examiners. The apprentices' ways of reflecting on their evolving professional performance differed, and there was no straightforward relation between their self-reflections and levels of performance.
\end{abstract}

Keywords: adaptive expertise, forensic science, fingerprint examination, apprenticeship, professional training, professional performance, professional practice, professional vision 


\section{Introduction}

The present study focuses on examining expertise in one of the oldest methods in forensic science, fingerprint examination. This study addresses tensions and discrepant relations between the developments of individual expertise and historically learned and socially constructed, collective practices. Traditionally, fingerprint examiners have been trained internally by crime-investigation laboratories and organisations relying on apprentice-mentor settings. The training of fingerprint examiners, as well as quality considerations, relied strongly on local practices, practical professional experience and seniority based on accumulated experience rather than validated professional competence. This is clearly illustrated in the debates between the communities of fingerprint examiners and forensic science experts (Cole, 2001).

Challenges of fingerprint investigation

Fingerprint investigation was once considered as the golden standard of criminal investigation and forensic science in general, providing indisputable evidence of an offender's presence at a crime scene. When erroneous analyses were encountered, individual examiners were typically blamed "attributing the error to incompetence, negligence, or fraud, insisting that, in the hands of competent experts, errors are virtually impossible (Ashbaugh, 1999; Cole, 2005)", quoted by Dror \& Cole (2010). In recent decades, fingerprint identification has faced crises involving questionable reputation due to misidentifications like the Mayfield case in the USA and Shirley McKie in the UK. These misidentifications have been attributed to changes in the socio-technical systems of fingerprint examination. The use of the vast databases in the Automatic Fingerprint Identification System (AFIS) for finding matching fingerprints for "latents" (i.e., fingerprints found from crime scenes) involves risks because of infrequent occurrence of highly similar 'random' matches (Dror \& Mnookin, 2010). ${ }^{1}$ Dror's investigations also indicate that contextual factors play an important role in analysis and interpretation of fingerprints. Dror and Charlton (2006) gave fingerprint experts series of fingerprints to analyze without informing them that had actually been previously analyzed by the experts themselves. Contextual information, such as evidence supporting positive identification ("the suspect confessed to the crime") or negative information ("the suspect was in prison at the time of the crime), made two-thirds of investigators make decisions that conflicted with their earlier interpretations (e.g., change to individuation, exclusion or cannot be decided). Overall, the experts made inconsistent decisions in $16.6 \%$ of the cases; however these inconsistencies were only seen when the target prints were so vague and ambiguous that they were hard to match with exemplars. Awareness of a colleague's decision tends to confirm rather than disconfirm erroneous judgments of identification. Also many investigators have shown wide variations in results and interpretations for fingerprint case work involving erroneous exclusions, missed identifications, and inappropriate inconclusive and no value decisions (Black, 2012; Dror \& Charlton, 2006; Kruger \& Dunning, 1999; Ulery, Hicklin, Buscaglia \& Roberts, 2012). Due to the absence of shared rigorous investigative standards, examiners make judgments based on the sufficient similarities of visual patterns (Cole, 2001; Mnookin, 2008). With recent novel elements of technological possibilities, changing nature of work, and also quality and transparency requirements are challenging forensic service providers focusing to open the "black box" for evaluation of services' credibility and reliability. Fingerprint experts are accountable for their identifications and could be summoned to testify at court so that beyond contributing to their own field, they need interactive capabilities of justifying their judgment and decisions to outsiders (Collins \& Evans, 2007).

\footnotetext{
${ }^{1}$ See Appendix A for glossary of fingerprint examination terms
} 
The role of professional vision in fingerprint investigation

Expertise in fingerprint examination relies to a great extent on pattern recognition (Dror \& Cole, 2010). In the same way as radiologist or fighter pilots, fingerprint examiners use the powerful human visual system as their central instrument for making judgments. Professional fingerprint examiners are carefully screened from a large number of candidates according to their personal capabilities to recognize visual patterns. They have to be able to combine their vision, speech, gestures, and other embodied resources to make sense of the fingerprint images (Styhre, 2010). The task of analyzing fingerprints is very hard because each fingerprint is unique. Latents collected from crime scenes are often partial and distorted; examiners have to be able to determine in uncertain circumstances whether latents and ten-prints found from archives indeed come from the same person. Rather than being a one-directional flow of information from the outside to the inside, pattern recognition is a constructive process driven by a participant's own culturally mediated schemes and expectations (D'Andrade, 1992; Neisser, 1980). A central aspect of expertise in fingerprinting is a deliberately cultivated professional vision (Goodwin, 1994), i.e., experiencebased and socially organized visual capabilities needed for "seeing" (perceiving, recognizing, comprehending, and interpreting) signals and events of fingerprint images relevant to the interests and purposes of the fingerprint examination community. Professional coding represents transformation of observed phenomena into the categories and relevant events of the profession (Goodwin, 1994). Accordingly, examiners' visual cognition is socio-culturally shaped by deliberate and sustained training to recognize normatively determined meaningful patterns (Fleck, 1979). Extended deliberate training gradually builds the required visual competencies that allow professionals to recognize meaningful patterns in spite of partial, noise-laden, and distorted information. The professional vision emerges through this noise and is embedded in the systematic coding, highlighting of fingerprint images and producing and articulating associated material representations (e.g., documentation). Producing and articulating material representations make phenomena in this complex perceptual field salient by marking and highlighting them in some fashion.

Current practices of professional vision in fingerprint examination are mediated by the Automated Fingerprint Identification System (AFIS) and such image processing and visualization instruments as Photoshop. These technologies allow representing, manipulating, transforming, marking, and sharing digital fingerprint images. Fingerprint experts need to adapt and transform their routine practices according to various affordances provided by digital technologies (Gegenfurtner, Siewiorek, Lehtinen \& Säljö, 2013). From working with digital rather than physical samples of fingerprints and the associated possibilities for manipulating the fingerprints in various ways emerge new challenges regarding the quality of the images and the reliability and validity of interpretations. It is possible to simultaneously collectivize fingerprint examination processes in terms of engaging several examiners working independently on the same sample so as to avoid bias effects (see Kassin, Dror \& Kukucka, 2013) during the identification processes. In order to make investigative practices more transparent, explicit, and systematic (rather than contextual, tacit, and local), it is essential that fingerprint examination communities develop and utilize shared frameworks and guidelines regarding coding, highlighting, and documentation the fingerprints being examined. At the moment, fingerprint examiners employ the ACE-V (Analysis, Comparison, Evaluation, and Verification) methodology as a framework for their activities (see SWGFAST guidelines, 2014; Ashbaugh, 1999). This framework has many limitations that allow fingerprint identification to be based on more local and personalized criteria than desirable (see NIST \& NIJ, 2014; NIJ, 2014, 2010; NAS, 2009).

\section{Cultivating adaptive expertise regarding fingerprint investigation}

The present study focuses on examining the development of expertise in fingerprint examination of two apprentices participating in a training program designed to elicit adaptive expertise (Hatano \& 
Inagaki, 1992). Toward that end, the aim was to train examiners who beyond mastering practical visual capabilities and procedural skills of fingerprint examination would be able to reflect on their investigative processes and use conceptual and theoretical knowledge to justify their professional interpretations and decision. The apprentices were engaged in appropriating socio-historically evolved concepts and methods of the field and acquiring an adequate body of visual and procedural skills and routines through formal and informal learning activities. Within Hatano's framework, professional routines may be seen as highly specific cultural tools whose straightforward application in typical cases easily leads to errors (Cole, 2007). Instead of straightforward adoption of established routines, adaptive experts are considered to be characterized by their deliberate efforts to understand the meaning of professional practices and associated inventive and flexible performance (Hatano \& Inagaki, 1992). Although routines can be exploited in most of cases of fingerprinting, examiners frequently encounter challenging cases whose solutions require going beyond routines and established procedures. Adaptive expertise entails procedural flexibility in terms of adapting existing procedures according to cases encountered and critically reflecting on mistakes and errors (Rittle-Johnson, Star \& Durkin, 2012). The flexible and adaptive use of procedures requires the integration of procedural knowledge with visual and conceptual ones adopted in an application context. Toward that end, it is essential to work with different cases, apply multi-faceted procedures, and enact diverse reflective practices (Lin, Schwartz \& Bransford, 2007).

Rather than simply adopting and mastering local and potentially maladaptive practices of fingerprint examination, the apprentices were engaged in reflection on action (Schön, 1987) through constructing extensive learning diaries, producing numerous research reports, and taking part in the developmental meetings of the fingerprint community. As Gruber, Harteis and Rehrl (2008) have argued, practice without theoretical reflection does not lead to in-depth learning. It is critical to invest a great deal of effort for reflecting on and generalizing experiences so as to learn from errors (Gartmeier, Bauer, Gruber, \& Heid, 2008; Leicher, Mulder, \& Bauer, 2013). Engaging novices to reflective practices is likely to deepen their understanding, systematize their knowledge, and gradually build a more coherent framework for their investigative activities. In order to cope with truly challenging situations, experts may have to be able to synthesise professional knowledge going beyond the boundaries of their discipline when necessary (Novotny, 2003). Adaptive expertise may also be understood as adopting a new social role of developer or transformer of professional practices (Mieg, 2006). In the context of apprentices' development toward adaptive expertise, phases of belonging, becoming and being are tightly intertwined with the goal of sociallyreflective dialogical participation (Billett, 2008; George \& Bennett, 2005). Through observation and interaction with experienced examiners' work, newcomers increasingly experience belonging to a workplace community. They become experts through sustained progressive problem solving (Bereiter \& Scardamalia, 1993) and applying and integrating professional knowledge and skills. When professional enculturation is successful, they will be experts with advanced metacognitive skills and a sense of professional identity (Chan, 2013). This pursued flexibility is related tightly to the skilled and efficient use of visual, conceptual, and procedural knowledge (Rittle-Johnson, Star \& Durkin, 2012).

The present investigation was socio-culturally in nature; we have been influenced by sociocognitive theories of expertise (Bereiter \& Scardamalia, 1993; Hakkarainen, Palonen, Paavola, \& Lehtinen 2004; Hatano \& Inagaki, 1992; Lin, Schwartz \& Bransford, 2007), theories of learning through participating in professional practices (Lave \& Wenger, 1991) as well as cultural historical activity theory (Engeström, 1987). We aim to develop cognitive theories of expertise toward a socio-cultural direction as well as adapting activity theory and participatory theories of learning to examine personal developmental trajectories of learners. Adaptive expertise is not only a matter of personal professional competence but also, to a significant degree, represents shared practices and methods of expert cultures and networks (Bereiter \& Scardamalia, 1993; Hakkarainen et al., 2004). 
Fuller and Unwin (2004) argued that "restrictive" professional learning environments transmit rigid routines and narrow practices and provide limited opportunities for the development of the highest levels of expertise. Expansive environments, in turn, engage professionals constantly in deliberate efforts of learning, professional reflection, and stretching of competence. Expansive professional communities may establish shared and collective practices and routines that push experts to function in a more sophisticated and critical manner. Because of the introverted tradition of the investigative professions, there have been challenges in determining the best investigative practices and cultivating shared national and international norms of investigation. However, forensic institutions have constant urgent needs to be able to apply modern educational methods in the training of a new generation of fingerprint experts. By developing shared concepts, methods, and practices of fingerprint analysis and by having the same fingerprints examined independently by several examiners (to reach concordant judgements), criminal-investigation communities may facilitate critical thinking and more rigorous shared investigative norms may emerge. In order to collectively share various aspects of expertise, professionals need to cultivate skills and competencies of reflecting on their professional activity at a meta-level and engage in critical professional discourse (Collins \& Evans, 2002, 2007).

\section{Forensic Laboratory as a research context}

The present study was carried out at the Forensic Laboratory of the Finnish National Bureau of Investigation (NBI), where there are about 125 experts with differing specialisations, such as DNA, fingerprints, handwriting, documents, shoe and tool marks etc. The Forensic Laboratory (accredited by and following the SFS-EN ISO/IEC 17025 standard) is responsible for assisting and training the law enforcement officials involved with crime investigations in Finland. Within the laboratory, there is a small number (10) of professionally qualified examiners specialized in analysing and identifying fingerprints. The turnover of the personnel is very low so that new apprentices are only seldom hired by the laboratory. This investigation took place in the context of a major transformation regarding instruments and methods of fingerprint examination that involved moving from actual physical samples to digitalized fingerprint data mediated by the Laboratory Information Management System (LIMS) as well as a changed division of labour (distributing the examination of fingerprints between several independent investigators instead of each investigator being responsible for his or her "own" cases). Because new quality, reliability, and transparency requirements have been considered to emerge from such transformations, the Forensic Laboratory has set high requirements and expectations for the expertise of new fingerprint examiners. Accordingly, adaptive expertise has been considered critical for investigative working habits and sophisticated conceptual competencies together with flexible procedural skills supported by the laboratory's professional learning environment being cultivated toward a more expansive direction.

In Finland, it is not possible to have a university degree in forensics; almost all such training has to be implemented and organized inside the Forensic Laboratory. In 2009, the laboratory modernized the fingerprint experts' training programme with the features of apprenticeship type learning and social formation of expertise (see Mustonen \& Himberg, 2011). The training was intended to become more transparent as well as collaborative in nature in terms of encouraging experienced examiners to share their knowledge and skills with novices, flexibly connecting and adapting learning across time and space (Fuller \& Unwin, 2011; Guile, 2011; Lave \& Wenger, 1991). Toward that end, the importance of giving trainees constant feedback and engaging them in collective efforts of critically assessing methods and transforming practices of fingerprint examination were emphasized. The programme contained exact quality and assessment criteria as well as explicitly defined organizational roles and responsibilities. The training programme consists of 120 credits (about 2 years' studies), as a simulation of an academic master programme to be carried out mostly inside the Forensic Laboratory. The trainees were required to have a bachelor's 
degree, preferably in natural sciences. The programme consists in six (6) parts, i.e., Orientation and communication studies (18 credits), Basic studies (17), Professional studies (35), Specialization studies (30), Scientific study (20), and a Final exam. Each part involves special study modules, such as concepts of fingerprinting, ACE-V methodology, palm prints, and detection methods in fingerprinting. Practical training is included in many modules, such as AFIS (Automatic Fingerprint Identification System) modules, Practical Training modules I-II and ACE-V methodology modules. Apprentices have to produce a written diploma report corresponding to the requirements of a Master's level academic dissertation.

Evaluation of trainees' professional performance was carried out by internal evaluations with oral and written tests, regular meetings and also external assessment by an outside expert at the end of the training process. The training was widely documented, and apprentices' development was repeatedly evaluated with detailed feedback. The programme was designed to provide a platform for the career-long development of the trainees' expertise. Its stated primary goal was to educate high-quality adaptive experts in fingerprint examination, identification, and analysis with strong visual, practical, and conceptual competences.

The aim of the present study is to examine the development of expertise in fingerprint examination by two new apprentices who were the first ones to go through the novel training programme. This study was aimed at answering the following research questions: 1) How did the two apprentices' professional vision regarding fingerprint examination develop? 2) What kinds of agentic efforts did the participant engage in to improve their professional performance? 3) How did the apprentices reflect on their developing professional performance and how did this relate to their level of accomplishment? 4) What kinds of professional learning network emerged to support the participant professional conduct? 5) What kinds of validated professional competences were acquired throughout the training process?

\section{Method}

\subsection{Participants}

The two apprentices were hired by the Forensic Laboratory in spring 2011. Altogether 412 candidates applied for the positions; 45 applicants were invited to a Forensic Laboratory selection test on the basis of their qualifications, professional experiences, and other relevant factors. The selection test consisted of five series of comparison and pattern recognition tests, e.g. a stimuluspattern recognition task requiring the identification of two identical images from several candidates within a certain period of time. After interviewing the 10 best performing candidates, the two apprentices, referred here with the pseudonyms Mary and Jill, were selected. The two selected apprentices started their work at the beginning of 2011 and finalized their training in 2013. All of the experienced fingerprint examiners of the Forensic Laboratory $(n=10)$ took part in training the apprentices in accordance with the collaborative training philosophy adopted. The first author, who is a former fingerprint examiner and forensic scientist, and was responsible for quality-development of methods for fingerprint examination during that time, functioned as the supervisor of the training process. Such a role allowed her to carefully trace the training process through documented examinations of fingerprints and learning diaries.

\subsection{Methods of data acquisition}

The present investigation relied on content-rich data that allowed the tracing of several aspects of the apprentices' professional learning and development. The case study data consisted of the repeated interviews, learning diaries, documentation of fingerprint analyses, and delayed selfassessment of the apprentices listed in Table 1 (Krippendorf, 2013; Neuendorf, 2002). In order to 
protect the anonymity of the apprentices, the data will be analysed as a whole as far as possible; differences between the participants will be examined only in relatively neutral contexts.

Permissions to use this data have been obtained both from the NBI and the apprentices themselves.

Table 1. A summary of data for fingerprint training.

\begin{tabular}{|c|c|c|c|c|}
\hline \multirow[b]{2}{*}{ Bodies of data } & \multicolumn{2}{|c|}{ Jill } & \multicolumn{2}{|c|}{ Mary } \\
\hline & $\begin{array}{l}\text { Length in } \\
\text { words }\end{array}$ & $\begin{array}{c}\text { Number } \\
\text { of pages* }\end{array}$ & $\begin{array}{c}\text { Length in } \\
\text { words }\end{array}$ & $\begin{array}{l}\text { Number } \\
\text { of pages* }\end{array}$ \\
\hline Interviews (interviews at the beginning, middle and end of training) & 1710 & 5 & 2162 & 6 \\
\hline Reflective learning diary & 52831 & 148 & 73261 & 172 \\
\hline $\begin{array}{l}\text { Documentation of Practical Training I and II documentations } \\
\text { (consisting of fingerprint images and textual documentation)** }\end{array}$ & - & 298 & - & 224 \\
\hline Delayed self-assessments & 1115 & 4 & 348 & 2 \\
\hline TOTAL & 55656 & 453 & 75771 & 404 \\
\hline
\end{tabular}

\section{Repeated interviews}

Semi-structured interviews were administered at the beginning, in the middle, and at the end of the training programme. The apprentices were asked to reflect on their professional expectations, experiences, and competence needed for fingerprint investigation. The interviews took 20-45 minutes and were audio recorded in their entirety. Only those parts that were considered relevant for carrying out the present analysis were transcribed.

\section{Reflective learning diaries}

In order to elicit reflection-on-practice, integrate practical and conceptual knowledge, and make professional learning visible, the two apprentices were asked to collect an extensive portfolio of their training and achievements, consisting of learning diaries and documentation of analysed fingerprints (compare Fuller \& Unwin, 2004, 2010). The portfolios included reflections on personal goals, performance, skills, learning, expectations, frustrations and challenges, demonstrations of knowledge and skills (essays, practical training, exercises, drawings etc.) and also assessment and feedback of the training and professional learning process. The apprentices were instructed to gather rich documentation of practical training and lessons as well as produce written reflections on their learning experiences. The portfolios were regularly reviewed and discussed in formal assessment meetings (apprentices, the supervisor, the quality manager, the group manager of fingerprint examiners), and also in informal working meetings between the apprentices and the supervisor.

Training through analysing fingerprints

The apprentices' skills and competencies in fingerprint examination were facilitated through various activities. Principles, procedures, and practices of fingerprint examination were explained through practical training, ACE-V methodology, and AFIS courses. During Practical Training modules I and II, the apprentices analysed, compared, made decisions and documented their fingerprint examination, comparing their solutions with those of experienced fingerprint examiners in accordance with the quality requirements of the Forensic Laboratory. The criteria for accepted performance during Practical Training I and II, was to end up with the same conclusion as the experienced examiner. However, during the feedback session, the trainees' perceptions, interpretations and decisions were reflected on and discussed. Practical training of fingerprinting took place across several training modules; this study focused on analysing data related to Practical Training I and II. 
In Practical Training I, the two apprentices were matched person with person with two experienced examiners working with them; they had the same 58 unknown latents (i.e., fingerprints found from a crime scene) to analyse, make AFIS searches and comparisons with ten prints (i.e., archived fingerprints of criminal offenders), and they had to make a decision regarding identification. They were instructed to document these phases and descriptions in terms of colour coding of fingerprints examined (see Langenburg \& Champod, 2011), written annotations of AFIS searches, and the participants' judgments and decision. The cases had previously been solved by identifying the fingerprints, but this information was not revealed to the participants. After analysis and AFIS searches for 4-5 latents, they had a debriefing meeting with experienced examiners going through the process and decisions. Altogether 58 unknown latents for each of the apprentices and their experienced examiners were examined across Practical Training I. The first author went carefully through all documentation and checked and double checked analyses of each case across the two apprentices and the senior examiners. This makes a total of $(2 \times 2 \times 58=232)$ latents with associated multiple AFIS-searches during the process.

The Practical Training II course involved the two apprentices working with their respective trainers, doing actual fingerprint examinations; Jill working with 227 and Mary 289 latents. Some of the cases involved actual identification, others did not. Each identification or non-identification was confirmed by a professional examiner who independently analysed the latents and confirmed or rejected the decisions. The apprentices were guided to use all the professional fingerprint examiners of Forensic Laboratory as co-examiners so as to learn to work with all of them. When they misidentified a fingerprint, feedback provided by the professionals facilitated their reflection on various aspects of the analysis and performance. The written documentation of experienced examiners in Practical Training I-II was not analysed, only the documented images of the fingerprints. The authors went through all the apprentices' activities during Practical Training II, and analyzed in detail seven fingerprints cases by Jill and six by Mary (often including several fingerprints and color codings).

Testing and delayed self-assessments regarding the competencies of fingerprint examination

The apprentices took part twice in the CTS (Collaborative Testing Services) and once in the ENFSI (European Network of Forensic Science Institutes) tests that are regularly administered to fingerprint examiners; the results demonstrated their acquired professional competencies. The apprentices were, further, asked to reflect on their professional expertise nine months after completing the training together with professional examiners giving feedback on their learning and socialization to the fingerprint community.

\subsection{Methods of data analysis}

During the two practical training modules, the apprentices and their teachers (experienced fingerprint examiners) produced documentation (images, codings, and written annotations) on analysis, comparisons, and decisions regarding fingerprints. The data were qualitatively analysed in detail according to Goodwin's (1994) categories of professional vision; coding, i.e., examining latents by marking minutiae (i.e., identifiable details and events in fingerprints) either automatically or manually in AFIS, highlighting (marking disturbances, colour coding ridge flows), and constructing external, material representations embodying their analyses and interpretations by using AFIS and/or Photoshop and producing written annotations. The analytic procedure was developed in the context of parallel investigation developed by the present investigators working with Juha Tuunainen and Pasi Pohjola focusing on contradiction meetings of professional fingerprint examiners that ended up with conflicting interpretations. From each fingerprint case, we analysed minutiae identified by the apprentices and senior examines and traced the process of associates AFIS searchers, and the resulting judgments; this data together with the investigator's 
notes were written to an Excel file. We were able to pretty straightforwardly distinguish the categories of professional vision from one another. In some cases, however, fingerprint analysis was only poorly documented both by the senior examiners and the apprentices. The analysis focused on comparing the apprentices' developing practices of professional vision (documented coding, highlighted perceptions, and annotated interpretations) with one another and with those of their instructors. The final decisions were made as reflections between the apprentices and experienced examiners. Because of the confidential nature of authentic fingerprint data used, we cannot provide complete case descriptions.

The participants' professional reflections were qualitatively analysed (Krippendorf, 2013; Neuendorf, 2002) on the basis of interviews and learning diaries using ATLAS.ti 7.0 software. The analyses were focused on finding indications of adaptive expertise that go beyond straightforward adoption and mastery of rigid routines. In this regard, it appeared relevant to relate practical experiences with conceptual issues, reflecting on obstacles and frustrations regarding the apprentice's evolving performance, struggle to understand the rationale of professional routines and practices; their reflections on their personal strengths and weaknesses as a fingerprint examiners, critically problematizing prevailing professional practices, their orientation towards seeking more rigorous methods of investigation, and reflecting on their identities and roles as fingerprint examiners. First, the researchers read the material several times, analysed it preliminarily, and categorized text segments relevant to assessing the apprentices' professional development in one hermeneutic category. The encoded material involved the participants' reflections on 1) relations between examination practices and professional knowledge, 2) skills and competencies required by fingerprint examiners, 3) ideas and reflections concerning how methods of fingerprint examination should be examined, 4) various challenges and frustrations encountered, and 6) networking practices. We analysed also how the apprentices built their personal professional network within the Forensic Laboratory, familiarized themselves with field units of crime investigation, and created contacts with various national and international external collaborators; the networks were visualized using the Cytoscape program. Overall, the categories emerging from the analysis corresponded closely to the instructions given to the participants regarding issues they should address in their learning diaries. Because the diaries were already partially structured according to corresponding themes, the analysis was rather straightforward and diverging interpretations easy to sort out. The analysis was carried out so that we identified the principal themes, conducted ATLAS.TI categorization, read the material regarding each thematic data area carefully, adjusted and modified the categorization, finalized the analysis and used both excerpts and qualitative descriptions to characterize the data.

\subsection{Describing the process of fingerprint examination}

The fingerprint examination process in Finland, consists of four phases; registration, screening, identification and statement production (Figure 1). In each phase, fingerprints are analysed and documented either more generally or more precisely. Every phase is instructed according to the Forensic Laboratory quality system and according to standard SFS-EN ISO/IEC 17025. In each phase, there are different examiners involved. The appendix explains the central terms used in fingerprint examination.

Firstly, examiners during make a "quick" analysis and evaluation of the quality of the fingerprint and decide whether it is good enough to be analysed. If the latents quality is good enough, it is sent to another examiner for the screening phase. If the quality of all the latents of a case is poor and they do not fulfill the quality criteria the whole case will be send through LIMS for statement production. Then a statement production examiner after quality checking produces the statement. 
At the second phase (screening), a fingerprint examiner does a more complete analysis. Examiner will analyze e.g., the quality of the latent, the overall ridge flow of the latent (is it a finger, palm, foot or other), clarity, the pattern type (e.g. arch, whorl, left or right loop), the quality and tolerance of the latent and identify different minutiae etc. (see NIJ, 2014). This is based on the ACE-V method (Analysis, Comparison, Evaluation, Verification) adopted by the Forensic Laboratory. If the latents quality is enough for further examination, all the case fingerprints will be compared to the suspects' fingerprints, but also they would be compared to the fingerprints of people who had legitimately been at the scene of the crime.

If there are unidentified latents left after the comparison, the examiner will carry out AFIS searches. AFIS searches can be done several times using different strategies e.g. making all finger searchers or more specific searches, one finger at a time, searches with automatically coded minutiae by AFIS or minutiae coded by an examiner etc. The examiner can also enhance the quality of the latents with different kinds of AFIS tools. After the search, the examiner sometimes compares dozens of candidates provided by AFIS and tries to find matches. If the search result is negative, a statement is produced. If a match is made, then the examiner at the screening phase, sends the latent to two independent fingerprint examiners via LIMS. Independent second examiners do the analyses and make decisions without knowing the first examiners' results. If decisions are consistent, the latent will be added to the statement of the Forensic Laboratory. If the results of the two examiners do not match, there is a discrepancy meeting and the result of this meeting is that a statement will be produced in the last phase, statement production. Every official decision of identification needs two identifiers, who have done their analyses and made their identification decisions independently in the identification phase.

All the documentation should be completed with the help of technical instruments, e.g. AFIS, Photoshop and LIMS (Laboratory Information Management System). The report of conclusions is automatically produced at the statement production stage with the help of LIMS.

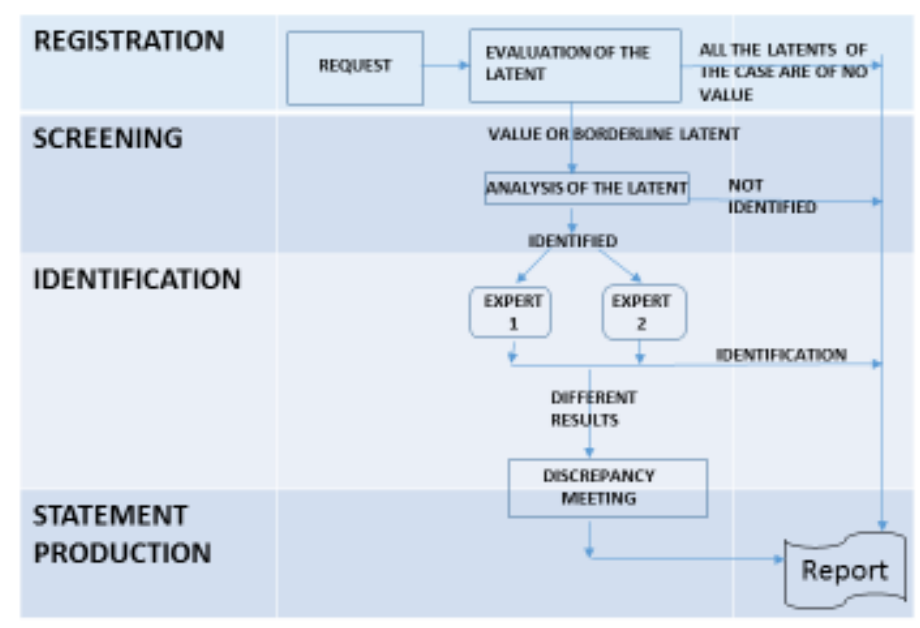

Figure 1. Fingerprint examination process. 


\section{Results}

In what follows, we describe the basic training (Practical Training I) through which the apprentices cultivated their professional vision by analysing the same series of fingerprints. Secondly, we will outline the advanced training (Practical Training II) that involved the apprentices examining their own fingerprint cases with a number of external examiners. Thirdly, we will reveal how the apprentices themselves reflected on their professional development. Fourthly, we will describe the learning network that the apprentices were guided to create. At the end of the results section (subsection 4.5) we will report the assessment of their competences and delayed self-reflections.

\subsection{How did the apprentices' professional vision of fingerprint examination develop?}

Across Practical Training I, the two apprentices examined the same series of fingerprints as the two experienced examiners working, respectively (1-1), with them. The apprentices were trained to use various methods of coding and highlighting fingerprints so as to learn to identify significant signals and events and determine the relevant facts in each latent. During the exercises, the apprentices' task was to work intensively with fingerprints (unknown latents). Working with AFIS, they were trained to correct the latents' orientation, use various enhancement tools for increasing contrast, reverse black and white colours of ridges, enhance the levels of an image so as to give a stronger depth or 3D impression or change the darkness of the latent and so on - this assisted in seeing the events and signals in the latent more clearly. Highlighting with Photoshop, included for instance, colouring usable and non-usable (i.e., blurred or otherwise disturbed) areas of latents. Quite often, there were two over-lapping latents; colour coding can be used to assist in separating them from one another. The apprentices also highlighted latents when trying to enhance uncertain ridge flows, disturbances caused by detection methods or trying to make interpretations of uncertain pattern types. After analysing unknown latents, apprentices and experienced examiners made searches using the AFIS database. Also the apprentices were asked to highlight their documents with written annotations while working with image representations (see Figure 2).
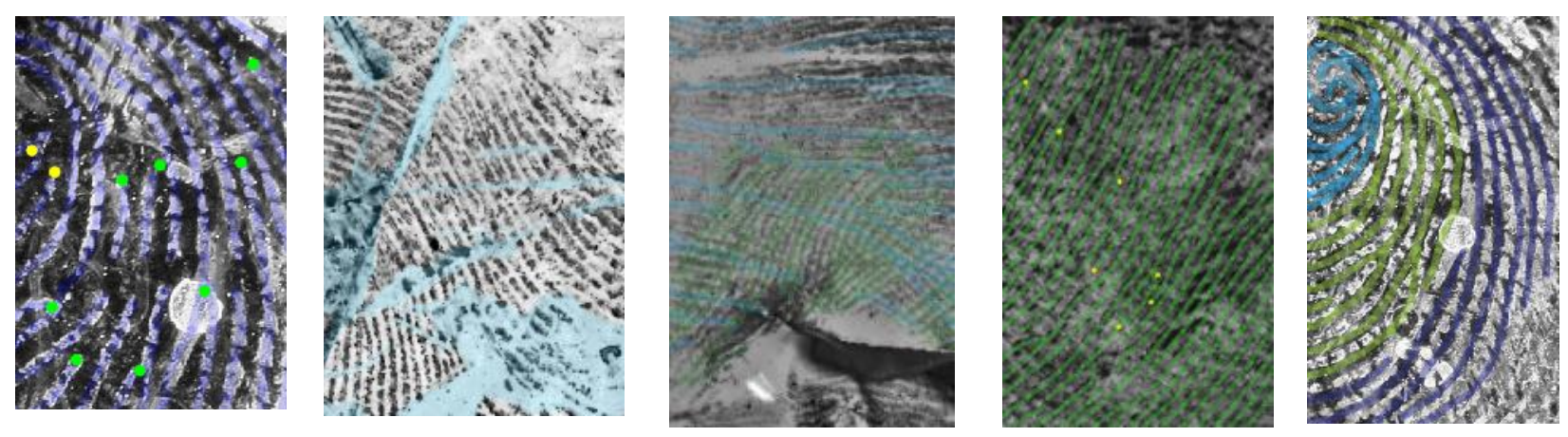

Figure 2. These five images provide examples of various ways of highlighting fingerprints done by the two apprentices during Practical Training I. In the first example, marking clarity of minutiae to latent by applying GYRO colour coding (GYRO system; colours of green, yellow, red, orange are based on the coding and highlighting of expert's perception and interpretation, see Langenburg \& Champod, 2011). Highlighting included using, for instance, PhotoShop for colouring ridge flows in blurred or otherwise unclear areas of latents.

During Practical Training I, the apprentices were provided latents from very easy to more challenging ones. In these progressive training sequences, decisions concerning the difficulty of the samples were made by experienced examiners. Most of the training practices consisted of doing codings of latents and making searches in AFIS, but the apprentices also used Photoshop for colour 
coding to help their decisions involving perceptions and interpretations. The aim of this kind of practice was to build an overall view of the AFIS searches and decision strategies, but also a comprehensive conception of the tolerances in latent searches. Using colour coding or screenshots with their technical tool AFIS or Photoshop assisted in highlighting and explicating perceptions and interpretations and communicating them to other examiners in the Forensic Laboratory. During this first practical training module differences were observed between the two apprentices regarding their familiarity with Photoshop; one apprentice used Photoshop in nine (9) cases, whereas the other one used it only in two (2) cases. This observation resulted in new Photoshop training sessions.

Table 2 presents an example of a latent analysed by the apprentices and their respective experienced examiners. Both of the apprentices used AFIS image enhancement tools to increase contrast in order to make examination of the latent easier. At the beginning of task, Mary identified six minutiae and performed an AFIS search with unknown pattern type without making a match. She tried to further enhance the image, deleted, added or re-located some of the minutiae and changed the pattern type to Left Loop and Whorl. She performed more than six searches for the latent without any positive result. After consulting an experienced examiner, she corrected the orientation as well as the location of some of her minutiae. When the orientation of the latent is wrong, AFIS often does not provide a reliable result; it can handle only \pm 30 -degree variations in orientation. After that, Mary was able to make a positive identification. However, she voiced some disagreement concerning a specific area in the latent involving blurring; she documented her analysis by colour coding using Photoshop. In the present task, Jill identified eight minutiae. She determined the right orientation of the latent. Her analysis indicated the latent to be either finger 7 or 8 (i.e., left hand fore- and middle-fingers); her first search with these fingers was successful. The data indicated that, in many cases, a certain fingerprint that was hard for Jill was easy for Mary and vice versa.

Table 2. Analysed data and image from one latent in Practical Training I material.

\begin{tabular}{|l|l|l|l|l|}
\hline & Mary & Jill & Examiner A & Examiner B \\
\hline Number of coded minutiae & 6 & 8 & 10 & 7 \\
\hline Pattern type & Unknown & Left Loop & Left loop; Whorl & Left Loop, Whorl \\
\hline Searched fingers with AFIS & $1,2,6,7$ & 7,8 & 8 & not documented \\
\hline Number of AFIS searches & more than 6 & 1 & not documented & not documented \\
\hline Orientation & wrong & ok & ok & ok \\
\hline
\end{tabular}

From the data it can be seen that the number or location of minutiae and fingers used in making AFIS searches diverged, sometimes strongly, between the apprentices and also between them and the experienced examiners. A corresponding difference in the tendency of making more cautious versus bolder coding was also observed in the coding of the experienced examiners. The difference between apprentices was that one of them coded more daringly every significant signal noticed in the latents whereas the other was more cautious and deliberate in coding. The apprentices' coding of minutiae concerning poor-quality latents often differed quite strongly from those of the experienced examiners; in cases of good-quality latents, the differences were not so drastic. Similar variations were also observed to occur between analyses of the experienced examiners. Table 3 reveals that Mary identified six minutiae, out of these, four were the same as Jill's; three and four minutiae (were different from those shared with Jill), respectively, were the same as those identified by Examiner A and Examiner B. Correspondingly, Jill identified eight minutiae, sharing four of them with Mary and six and seven minutiae, respectively, with Examiners A and B. All the participants had identified the same over-lapping minutiae but also identified some minutiae that the others had not marked at all. Fingerprints are information-rich so that from high quality latents one can identify dozens of minutiae; thus variation between examiners is not so important. The resulting identifications are not affected when latents are clear and diverging minutiae proportionally low. In latents of poor quality or with a low number of other signals and events, there are often only a few 
high-quality minutiae altogether so that variations in coding may have a significant impact on the result of an examination. Thus, if even one minutia is coded wrongly a match may not not found and the examiners may end up with different interpretations.

The apprentices reflected on the differences between their own evolving professional vision and that of the experts: "We examined fingerprints we had coloured and checked how [name of an experienced examiner] had coded them. There were many differences so that we both had coloured especially certain minutiae somewhat too boldly. In one of the latents being coloured, there were hardly any minutiae, but I had again marked about ten". They reflected on the experienced examiners' professional practices and addressed differences between examiners:" I was surprised when I realized on what a small number of minutiae [name of an experienced examiner] was willing to state that the fingerprint were the same, even if the minutiae were not so specific. The most confusing part is that I do not know how close fingerprints could truly to be one another, so that it is hard to estimate how from such small similarities it could be concluded that the fingerprints are the same." The other apprentice reflected; "Even examiners who have years worked in the same positions appear, however, to have their own, individual ways of observing the fingerprint patterns being investigated, and of making their own conclusions. Nevertheless, the end result is usually similar or at least not in strong disagreement with results that another examiner of the fingerprint could have ended up with."

Because of variation and different styles of coding and AFIS searches, the apprentices had to consult an experienced examiner two or three times during the practical training, when they did not find a match in AFIS. Consulting and having instant feedback from experienced examiners, appeared to play a very important role in the learning process. The aim was to learn from errors and to learn to reflect on them effectively as part of their practical experiences towards optimal problem-solving strategies. The aim was to avoid making serious and repeated errors again and learn to solve problems during the process. The data showed that during Practical Training I the apprentices' tolerance to cope with uncertainty narrowed. They also learned to use different strategies when working with AFIS. Before Practical Training I, the apprentices had been given basic training and professional studies in fingerprinting which they needed for Practical Training II.

\subsection{What kinds of agentic efforts did the apprentices engage in to improve their professional performance?}

During Practical Training II both the apprentices worked with the real cases and latents. They produced laboratory statements with the cooperation of all fingerprint examiners of the Forensic Laboratory. The cases were selected randomly and included all kinds of fingerprint material with different types and quality of latents. According to the apprentices' learning diaries, the stress of uncertainty in finding the "right results" increased during Practical Training II. Feelings of uncertainty are likely to be educative for the fingerprint examination because candidates taking the examination have to be sensitive to the risks of making errors due to varying quality of latents, uncertainty of procedures, and the limitations of AFIS technology.

The coherence of the apprentices' coding appeared to slightly improve during Practical Training II. The apprentices practiced hard and also became equally skilled in colour coding. In poor-quality latents, the variation of coded minutiae still varied between the apprentices and also experienced examiners. Nevertheless, as a result of analysing a large number of latents, the variation of minutiae between apprentices and experienced examiners appeared to have decreased. The apprentices tested different analytic strategies and used AFIS tools in a rather sophisticated way. Table 3 presents an example of analysing latents during Practical Training II: Mary coded 15 of the same minutiae as Examiner A and 17 of the same minutiae as Examiner B. Jill coded 8 and 9 of the same minutiae as examiners A and B. During the practical training, there were a few documented misidentifications 
and disagreements in identification between the apprentices and experienced examiners. Experienced examiners checked all the unsolved latents which the apprentices had processed. The apprentice's identifications were processed and documented by two experienced examiners according to laboratory's quality requirements.

Table 3. Example of the results of minutiae coding during Practical Training II.

\begin{tabular}{|l|l|l|l|l|l|l|}
\hline Case/Latent & Apprentice & $\begin{array}{l}\text { Number of } \\
\text { coded } \\
\text { minutiae by } \\
\text { apprentice }\end{array}$ & $\begin{array}{l}\text { Number of } \\
\text { coded } \\
\text { minutiae } \\
\text { by Examiner } \\
\text { A }\end{array}$ & $\begin{array}{l}\text { Number of the } \\
\text { same minutiae } \\
\text { as Examiner A }\end{array}$ & $\begin{array}{l}\text { Number of } \\
\text { coded } \\
\text { minutiae } \\
\text { by Examiner B }\end{array}$ & $\begin{array}{l}\text { Number of the } \\
\text { same minutiae as } \\
\text { Examiner B }\end{array}$ \\
\hline 1 & Mary & 21 & 15 & 15 & 18 & 17 \\
\hline 2 & Jill & 11 & 15 & 8 & 10 & 9 \\
\hline
\end{tabular}

Across their training and informal participation, the apprentices were trained and socialized into the professional practices of the Forensic Laboratory. They learned through trial and error to try out various search designs, seeking to find a hit (i.e., ten prints from a register corresponding to the latents). The training and socialization not only involved appropriating normative ideals but also tacit knowledge and maladaptive local practices. For example, some of the experienced examiners designated to coach the newcomers, guided them to do AFIS searches using only one or a few fingers. The standard operating procedure of the equipment developer is, however, to use all the fingers in first searches. It took time for the apprentices to acquire enough experience to realize that the standard procedure leads to more effective searches, especially in high (good) quality latents, and to reconsider their strategies. The apprentices failed many times to make hits because they performed the first AFIS searches with the wrong fingers and/or latent orientation. Although professional vision allowed the experienced examiners to reliably identify the correct fingers from latents, such visual competences were not cultivated enough in the cases of the apprentices. Sometimes the experienced examiners' own AFIS searches failed, but they were able to effectively correct their search design and get the desired hit results. The professional examiners had their own tricks for facilitating the process, such as scanning fingerprints being analysed in order to increase darkness and contrast.

During the training, the apprentices also encountered particularly difficult and tricky latents that caused a great deal of frustration. Sometimes the apprentices did not succeed in their identification attempts without assistance. A latent linked to case 11, was hard to analyse because it was chemically processed and the material was wrinkled plastic wrap. The apprentices examined it by removing and moving minutiae provided by the automatic (auto) coding of AFIS; they added minutiae of their own, changed the searched fingers, changed the orientation, removed all auto coded minutiae and personally marked all of them. They searched through 360 degrees and used unknown pattern type as a search criterion, modified the minutiae (removing uncertain ones), searched by zooming into a smaller area, searching with certain fingers and so on. Altogether, both of the apprentices carried out several searches without success. Only after consulting an experienced examiner, did the participants succeeded in their search. This took place by decreasing the number of minutiae; changing the pattern type to whorl, carrying out new auto coding, and removing uncertain minutiae. The difficulty was probably caused by the fact that the core of the latent looked different from their ten print counterparts; because of that the apprentices could not identify the hit listed by AFIS. 
Table 4. Practical Training I table from case 11.

\begin{tabular}{|l|l|l|l|l|}
\hline & \multicolumn{1}{|c|}{ Mary } & \multicolumn{1}{c|}{ Jill } & \multicolumn{1}{c|}{ Examiner A } & \multicolumn{1}{|c|}{ Examiner B } \\
\hline Number of analysed minutiae & 14 & 18 & 13 & 17 \\
\hline Pattern type & Whorl & Whorl & Whorl & Whorl \\
\hline Searched fingers from AFIS & $1,2,6,7$ & 6,7 & $1-10$ & 6 \\
\hline Number of AFIS searches & 6 & 10 & not documented & not documented \\
\hline Orientation & ok & ok & ok & ok \\
\hline
\end{tabular}

\subsection{How did the apprentices reflect on their professional performance and how did this relate to their level of accomplishment?}

In order to elicit the development of adaptive expertise, the apprentices were requested to extensively reflect on the development of their professional competencies. Across the training, the apprentices reflected on and assessed their plans of action, technical difficulties and strategies with AFIS, the severity of practical exercises, and how they had worked and discussed with different experienced examiners. The apprentices had somewhat different styles of self-reflection; one of them was more open and expressive when describing her experiences whereas the other tended to be more economical and reserved in her self-reflections. Also they differed in critical expressions. The first one had more of a critical orientation and boldly proposed various developmental ideas whereas the other was rather concise, deliberate, and reserved when describing her development.

In their interviews and learning diaries, the apprentices reflected on the requirements of the fingerprint examination, their own personal strengths and weaknesses, and their evolving professional competence. Both of the apprentices had noticed that effective fingerprinting required a systematic working style, involving exactitude and patience. The extent to which one needs to cultivate capabilities of concentrating had been surprising to one of them. The other apprentice expressed the corresponding idea: "patience, it will continue developing further, learn to endure monotonous work, and then, of course, you need to be focused for many hours in a day." Their reflections focused on assessing critical aspects of fingerprinting, such as identifying minutiae and analysing the way different material surfaces affected the fingerprints: "learn the basics, what are the important minutiae in the latent that can be identified; so you learn to see from the latent how it has moved and how it had touched the surface. "They also highlighted the importance of learning to recognize patterns.

The participants reflected also on their evolving professional self-efficacy. "Although I in principle trust in my capability of examining fingerprints and that the results are reliable, but uncertainty is caused by the fact that occasionally I have missed an identification or interpreted the orientation of a latent to be different form what it actual was. Still, somehow there is just now a lack of selfconfidence; what if I am not good enough?" She also writes, "Now I am not at all ready and I feel from the latents I have seen, I feel that I would not be able to identify some that other examiners have identified, but I am developing and learning all the time" and "The biggest challenge is to be able to make identifications using unclear latents." They emphasized the importance of being aware of one's own limitations so as to be able to ask for advice if necessary. Both mentioned that it is essential to be able to justify the basis on which decisions have been made.

During Practical Training II, the apprentices differed in documenting their perceptions and interpretations. One pushed her expertise toward the next level by analysing fingerprints and precisely writing up her perceptions and interpretations in a way that indicated she had an extensive knowledge of fingerprints. Her documentation included minutiae, ridge flow, and written analysis of 'noises' in the latents. She productively wrote about her technical decisions in the first practical module and her openness in reflecting on her performance and analysing her mistakes turned out to 
be her strength while analyzing data in Practical Training II. However, the other apprentice's approach in analysing the latent were very reflective during Practical Training I, but turned out to be somewhat limited during Practical Training II. She documented her analysis and decisions only with minutiae to the required documentation and added the rest of the information to the Laboratory Information Management System (LIMS), according the laboratory quality instructions. She appeared to imitate the minimal documentation practices of the experienced examiners she was working with; perhaps she wished to minimize writing and the amount of efforts needed for reporting examinations.

The apprentices reflected on their development of professional vision and learning process in their portfolios. One of apprentices was initially very confident; she reported that encountering various challenges, obstacles, and occasional failures had somewhat shaken her self-confidence. She reported, "I want immediately to do without unnecessary in-depth pre-reflections. I somehow feel that in the context of these latents, I will not accomplish anything if I keepthinking them before starting the analysis. It would be different if I knew where the fingerprints had been taken and how they were pre-screened for analysis." Further, "my routines for searching for fingerprints have rapidly started to form and I am clearly acquiring a certain habit for analysing latents. Perhaps I am also able to perceive somewhat more difficult latent differently and notice how small details can truly help make a decision regarding a hit." She recognized a phenomenon well known to investigators of problem solving as functional fixation (Mayer, 1992) that involved getting stuck with the first visual interpretation of a problem. "I have ... noticed that if you focus your attention on certain aspects of a latent, the perspective is hard to change later on. A new perspective is observable only after someone else tells youtelling about it. "Both apprentices found it challenging to learn how to effectively do AFIS searchers. "Altogether, I feel that after AFIS- and palm print training the level of my competence has tremendously improved and my working is much more confident than before. I especially feel that I am acquiring some sort of routine for searching for fingerprints, although certain latents cause more difficulties than others."

The other apprentice in turn, reported reflecting first and moving to act only after that. Initially she was reluctant to put effort into theoretical studies and did not appear to fully acknowledge their importance. Yet finally she came to theconclusion that those were useful aspects of the study program. "My ability to perceive different events in latents (much smallest details as well as more observable general ridge flows of broader areas, influences of disturbances) developed through examining numerous heterogeneous latents, and colouring and comparing them. As a function of training, also my sense of everyday practices of fingerprint examiners and associated challenges developed as well." She addressed improving professional capabilities in her learning diary: "Searching for fingerprints with AFIS, appeared to get easier latent by latent and finding the correct fingerprints especially when you have had to reflect for a long time: the coding of minutiae was especially rewarding." She had accumulated professional experiences that assisted in understanding various factors that affect the nature of observed latents. Yet, some latents caused feelings of frustration because they were hard to identify despite numerous searches.

Both apprentices worked through unclear, low quality prints and developed their own working hypotheses explaining why certain searches did not produce the expected results: One said, "I have learned through working with several practicing latents to better understand that the pattern types of latents could, for instance, because of various disturbances or access to mere partial fingerprint appear to be different from what they truly are [in ten prints]. For instance latents that I searched for as mere loops turned out several times to be pretty clear whorls." An important aspect of the development of expertise in fingerprint examination is to learn to use instruments and tools adaptively. When using AFIS, you could improve chances of doing a successful search by decreasing the number of minutiae, changing the location of minutiae, redoing manual coding (after auto coding), changing pattern type or changing the quality of the latent. Differences between auto 
coded and actual location of minutiae are emphasized in poor-quality fingerprints due to the background; type of surface and disturbances due to lateral movements or double taps.

In order to facilitate adopting a developer's role in fingerprint examinations, the apprentices were engaged in collective efforts to develop the fingerprint examination methods from scratch by taking part in workshops and discussions. The participants reflected also on the development of methods and criteria for fingerprint examination. They argued that it is not meaningful to go back to identifications based on the number of coded minutiae: "When the number of minutiae needed for identification is not predetermined, each latent is processed more individually (case-based way) and the examiner has to justify decisions made during careful identification to herself and other examiners". The apprentices were sometimes a bit frustrated by the vague criteria of coding: One said, "I was surprised also how hard it is to determine what minutiae should be marked green, it felt that you could have to mark most of the minutiae yellow marking. I have to constantly remind myself to consider how clear a clear minutiae is and where the boundary between yellow and green is." They also reflected on criteria for determining whether latents are sufficiently clear for examination; they argued that probability estimation could be used to examine poor latents; otherwise borderline cases are too easily categorized as "non-identifiable".

Toward that end, the two apprentices were requested to focus their final scientific studies on the development of fingerprint examination methods. One of them investigated the development of AFIS palm-print searches whereas the other one examined clarity, quality, and conclusions made concerning fingerprints. The first case involved testing, for instance, various styles of making palmprint searches and asking experienced international investigators associated structured questions. The other apprentice selected low quality-latents and asked experienced local and international examiners to assess their characteristics. Both of the apprentices were excited about the possibilities of expanding their work descriptions beyond mere fingerprint examination to developing methods for examination. One apprentice stated; "research project had been the most interesting tasks that I have thus far been responsible for. It allowed me to use different methods, examine certain specific area, invent associated solutions, and I like writing reports, it is fun to structure and synthesize my own ideas, make conclusions and define policies." The other apprentice stated that fingerprint examination is also exciting because "I have always been interested in quality systems, now I can apply them to this fingerprint analysis; that is what I would like to do, I am looking forward to it and already have some competence in it."

\subsection{What kinds of professional learning networks emerged to support participants' professional conduct?}

One of the central aims of the training program was to assist the apprentices to create professional learning networks rather than rely on mere personal experience or the unsystematic sharing of knowledge in small groups of peers. Toward that end, the study programme provided opportunities for collaborating and networking with diverse stakeholders, such as customers (units of criminal investigation), the European Network of Forensic Science Institutions (ENFSI), the NBI, several universities, and stakeholders of the home organization (the Forensic Laboratory), as well as colleagues and other experts, some with strong and others with weak ties. The interviews and learning diaries revealed that the apprentices understood the importance of networking for the respective trajectories of their future professional development and network. They reported better understanding the responsibility and role of the Forensic Laboratory as an organization for developing methods of criminal investigation. The importance of collaborative working and joint efforts of developing investigative method was understood. They reflected as follows: "as an entirety, this crime scene module was very interesting. I learned versatile research activities and it gave me lot of perspective in relation to the Forensic Laboratory fingerprint examiners (and other research areas examiners). I got a wider picture of the position of our work, and an understanding of 
how my own work is one loop in a long chain" and also "it has been very surprising how quickly the onsite crime investigations are done and how little useful material they find. However, it has been very interesting to follow the investigations and compare real performance with what I have learned in theory."

The apprentices were familiarized with various aspects of criminal investigation, including where samples are taken, how these arrive, and the working conditions of crime-investigation field units. They estimated that their collaborative efforts have become they came to know many people working internally and external to the Forensic Laboratory. It was reported that understanding and valuing the work of other experts increased across networking activities. The apprentices reported that they had developed a better sense of their own training and development challenges. They were oriented toward participating in further international collaboration within the frameworks of ENFSI and other European institutions. In order to be able to actively develop investigative methods, it is essential to expand one's perspective beyond established routines of local communities and familiarize oneself with the developmental perspectives of various stakeholders. New modern technology tools will provide the possibility to expand the network from micro-level relations to stronger and richer ones in the future. Figure 3 shows the personal learning networks of the apprentices.

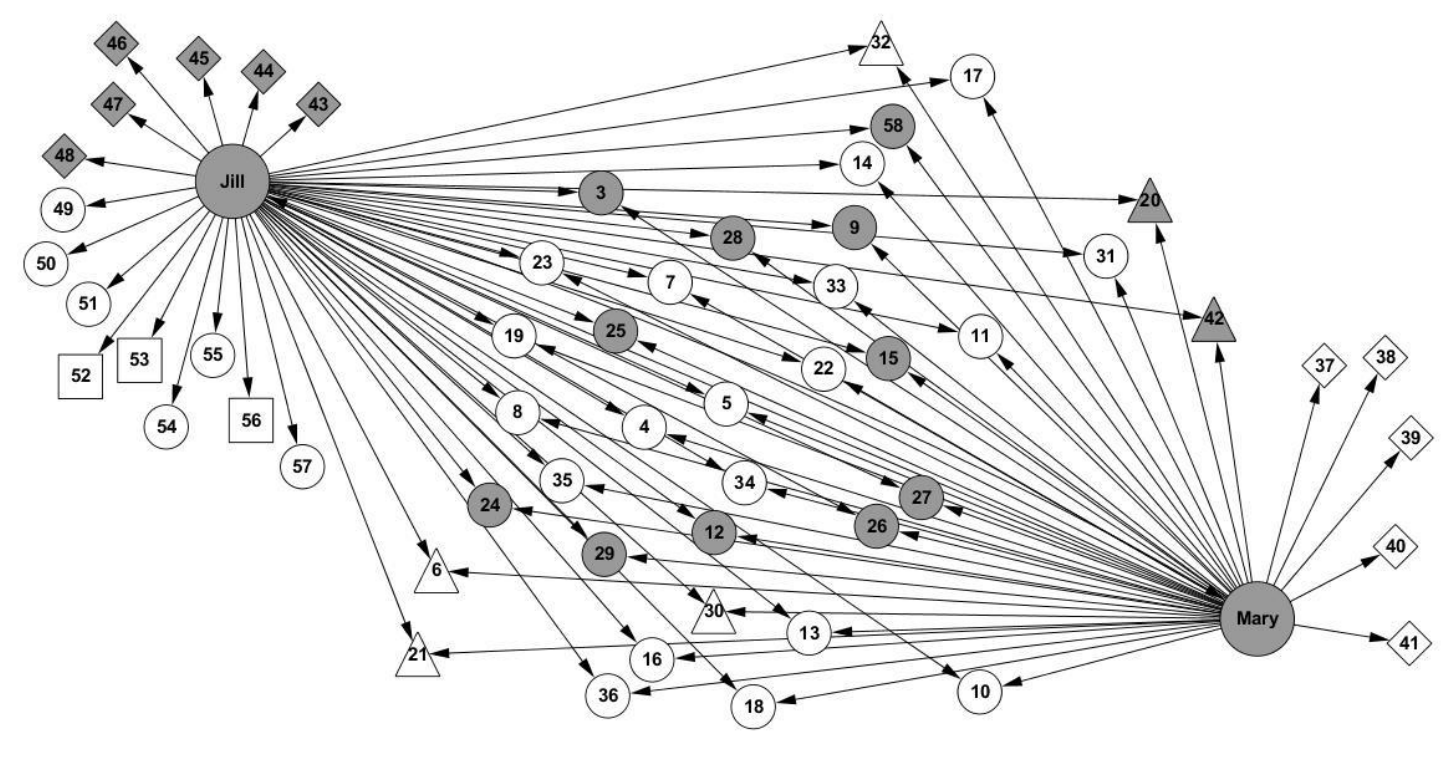

Figure 3. Personal learning networks of Jill and Mary. Internal actors are indicated by circles and external ones by other shapes. The shape and the colour code reveal are related to the participants' institution: the grey circle, the Fingerprint unit; white circle, the Forensic Laboratory; white triangle, the National Bureau of Investigation; white diamond, the Crime Scene Unit A; grey diamond, Crime Scene Unit B; white rectangle, the European Network of Forensic Institutes; grey triangle, University of Helsinki. The big dots represent the two apprentices and the small ones represent their network alternates. For every participant, we have provided a code identifying the institution and identification code number. The two apprentices' personal networks have been merged for the visualization. 


\subsection{What kinds of validated professional competences were acquired throughout the training process?}

In order to ensure the professional competence of fingerprint examiners, the Forensic Laboratory administers the CTS test (see Collaborative Testing Service Inc.) twice a year and every two years the very challenging ENFSI test (European Network of Forensic Science Institutes. The two apprentices took part in the CTS twice and the ENFSI test once during their training, together with other members of the Fingerprint Laboratory. The first CTS test took place during Training I, and the other at the beginning of Training II. The results indicated that both apprentices performed as competently as the professional fingerprint examiners, making no errors. In the ENFSI test one of the apprentices made no mistakes whereas the other one failed in some difficult cases that were hard also for some of the professional examiners. In the CTS test taken 6 months after they had finished their training, both apprentices were successful.

The two apprentices provided written reflections of their professional learning 7-9 months after they had completed their formal training. They reported having acquired "certain kinds of routines" that had supported sustained concentration on examining fingerprints. Their self-assessments indicated that their competence developed best through working with cases and learning from mistakes, although they reflected sometimes on their experiences of uncertainty regarding interpretation of unclear latents. One of them revealed that she had done more daringly analyses before consulting other examiners. Also they asserted that they have learned to know the limitations of their competence. One of the candidates claimed that her professional competencies have remained at the same level although she has become more certain and able to adapt her activity to the requirements of the professional procedures and shared guidelines. Her professional vision had developed in terms of being able to "mark carefully all the minutiae I have observed", being able to differentiate high- from low-quality latents and using automatic (AFIS) coding when necessary.

Both of them are currently taking part in training for police, crime scene investigators. Experienced fingerprint examiners acknowledged that the two apprentices had grown up to be full members of the community and valuable colleagues with whom they worked closely. It was appreciated that they were taking an active part in the development of methods fingerprint examination, in many case, pushing experienced examiners to justify their interpretations and decisions. The two apprentices claim that the fingerprint examination community had provided a very encouraging environment for cultivating professional competence.

\section{Discussion}

The overall purpose of the present investigation was to examine how adaptive expertise regarding fingerprint examination could be elicited. The new training program was designed to facilitate adaptive expertise by engaging the apprentices in 1) solving fingerprint cases with various levels of complexity, 2) working alongside many experts, 3) being provided with constant feedback from senior practitioners and academic advisors, 4) carrying out multi-faceted academic studies concerning the concepts and methods of fingerprint work, 5) participating in the development meetings of the fingerprint community, 6) pursuing their own research regarding fingerprint methods. Although it cannot be taken for granted that the enacted practices corresponded to the stated goals of the training program, it appears that the apprentices appropriated various practices relevant for the development of adaptive expertise. Both of the apprentices demonstrated some aspects of adaptive expertise although their long-term trajectories cannot yet be known.

The first problem addressed in the present study was the extent to which the two apprentices have appropriated the professional vision required for fingerprint examination. Overall, the notion of 
professional vision appeared rather straightforwardly to fit with characterizing the visual competencies relevant for fingerprint examination. The apprentices learned to code and highlight fingerprints and produce associated material artefacts under the guidance of senior examiners. Yet, they encountered many challenges when working with AFIS and Photoshop, such as learning adequate search procedures. Because there are no comprehensive quantitative and qualitative criteria for making decisions in fingerprint examination, it is still to a significant extent a matter of interpretation. Because there were no unequivocal solutions, differences between multitudes of interpretations caused a great deal of initial confusion for the apprentices. The main challenge appeared to be recognizing meaningful patterns in the latents being examined in spite of their poor quality. Although the apprentices' learning paths differed, they learned to use professional tools for representing, searching for, and comparing fingerprints.

A striking difference between the apprentices was, however, that one of the apprentices coded more daringly every significant signals she noticed in the latents whereas the other one was more cautious and deliberate in her codings. A similar tendency was also seen in the codings of experienced examiners; some of them boldly identified many minutiae, others did not document many aspects of their investigation, possibly because their examinations served only training purposes. Although the intention was to train the apprentices from the very beginning to more reflective practices of fingerprinting, the data revealed that their investigative styles often started to resemble those of the experienced examiners they were working with. However, there is not only one correct way of coding fingerprints, and adequate analysis may be reached through different approaches. By relying on various approaches, the closest "truth" can still be reached.

Secondly, we addressed the participants agentic efforts for improve their professional performance while successively analysing more challenging fingerprints. The apprentices pushed their expertise by trying alternative search designs and showed constructive self-reflection while actively assessing their performance and skills during their practical training as well as other training modules. Both of them acknowledged the importance of being able to deal with and endure uncertainty and occasional frustration. They considered it important to learn to manage monotonous work that requires constant concentration. They revealed that their capabilities for concentrating had been challenged many times and it had been frequently necessary to stretch their competencies. They were both investing a great deal of effort in learning and working at the edge of their competences. It is easy to see that seeking challenges and going beyond comfort zones characterized their practices.

Thirdly, we examined how the apprentices' practices of reflecting on their developing professional performance and how this was related to their level of accomplishment. In order to elicit selfreflection, the apprentices engaged in constructing extensive portfolios throughout their training. By engaging in textual practices of reflecting their activity, the apprentices documented their perceptions and interpretations in various modules of practice and in these activities also synthesized and integrated their professional knowledge. They reflected on the development of their own competences and looked for areas where they could improve. Moreover, they were engaged in collective efforts of improving methods of fingerprint examination, and their diploma work served that end as well. One apprentice did not provide reflections of her learning that were as rich as the other one but tended to describe her activities rather than thoughts and mental impressions. Analysis of differences between the apprentices could be summarized with the following conclusions: both showed personal strengths and weaknesses. But their conceptions of adaptive expertise and their self-reflection during coding were raised to new levels of professional functioning.

Fourthly, we asked what kinds of professional learning network emerged to support the participants' professional conduct. The apprentices learned to work with various national and international crime investigation units and created valuable personal ties. They acquired meta-level understanding of the roles and functions of different units and learned to appreciate their work. The 
experienced examiners turned out to have excellent contextual knowledge of fingerprint investigation as a whole and assisted in training and socializing the newcomers to the fingerprint community. The experienced examiners' ability to express and share openly their tacit knowledge with the two apprentices at every level astonished the first author. Many experienced examiners reported that continuous interaction with newcomers pushed, challenged and forced them to explicate their tacit knowledge.

Finally, we asked what kinds of validated professional competences were acquired throughout the training process. Objective performance measures based on the CST and ENSFI tests revealed that both apprentices acquired the necessary skills and competencies of fingerprint examination during their period of apprenticeship; they passed the CTS test at the same level as experienced, professional examiners. They did not, however, only appropriate adequate professional practices from the senior examiners, they also acquired maladaptive practices such as minimal or lacking documentation. Traditional professional competencies emerged through sustained personal practice. A limitation of such practices was, however, that fingerprint examiners did not have shared, specific conceptions either for justifying and articulating their decisions or communicating their analyses. Research and methods in the field have, however, developed rapidly: there is an enlarging body of concepts relevant for fingerprinting, such as ACE-V framework mediating practitioners' professional vision. Yet, a great deal of fingerprint analysis still relies on qualitative interpretations with opaque justifications based on the experience of professionals. Careful documentation of professional problem solving is an important aspect of quality thinking. In the future, the forensic laboratory will rebuild the structure of the portfolio toward forensic laboratory quality requirements and also in accordance with guidelines of future improvements in training and maintenance of competence. These kinds of practices raised transparency and reliability aspects at every level.

Fingerprinting training of the two apprentices was analyzed through documented examination of fingerprints, extensive learning diaries, and repeated interviews. In spite of the multi-faceted and content-rich materials, there were certain limitations that need to be taken into consideration in interpreting the results (Yin, 2009; Akkerman, Admiraal, Brekelmans \& Oost, 2008). Although the practical training involved solving a large number of fingerprint cases, some of them were not carefully documented. The instructions given to the apprentices affected what aspects of their training were documented in their learning diaries; the questions addressed correspondingly shaped their interview responses. The participants' personal styles of reflecting and talking about their experiences may have affected the nature of the data acquired. The experienced examiners' skills and competences in sharing knowledge were not analyzed.

When interpreting the results, it also should be taken into consideration, that the first author was responsible for training the two apprentices. This allowed closely following and facilitating the development of the apprentices. Her expertise was crucial also in analyzing the data regarding training cases of fingerprint examination. Although the present investigation was carried out as rigorously as possible, we cannot rule out a possibility that her involvement in the training process somehow affected the results and their interpretation. Further, the present case study focused only on examining two apprentices and, therefore, the results cannot be generalized across other cases and contexts. Nevertheless, the multi-faceted information collected allows various aspects of the development of the apprentices' professional experience to be traced. These aspects have to be considered in future investigations.

We started this investigation with the somewhat cognitively loaded notion of adaptive expertise as personal orientation toward conceptualizing practice, seeking challenges, and working at the edge of competence (Bereiter \& Scardamalia, 1993). It order to elicit this process, the participant engaged in the textual practices of building and comparing their learning diaries and discussing 
critical issues of fingerprint examination with senior examiners and the supervisor. Beyond the fast cycles of pattern recognition and case interpretation, the apprentices were engaged in more deliberate analyses of their professional activity, so as to assist the building of personal professional knowledge (Eraut, 2010). It was presumed that such knowledge practices (Hakkarainen, 2009) assist in explicating and re-mediating evolving professional competencies. By engaging the participants to use writing for reflecting on their activities, it was intended to elicit more explicit mediation of their professional activity. We see adaptive expertise as a socio-epistemic practice that shape apprentices' everyday working, and their relationships with the senior examiners they are working with. It involves second-order activity eliciting proactive adaptation to fingerprint work. Professional development is also a negotiation between collective norms and practices and participants evolving subjectivities and identities (Billett, 2011). It appears to us that the present apprentices, indeed, appropriated practices adaptive expertise in terms of cultivating their epistemic agency (Billett, 2011), i.e., their interest, motivation, and capability of learning and deepening participation in the expansive activities of fingerprint community. 


\section{References}

Akkerman, S., Admiraal, W., Brekelmans, M. \& Oost, H. (2008). Auditing Quality of Research in Social Sciences. Quality \& Quantity, 42, 257-274. DOI: 10.1007/s11135-006-9044-4.

Ashbaugh, D. (1999). Quantitative-Qualitative Friction Ridge Analysis: An Introduction to Basic and Advanced Ridgeology. New York: CRC Press LCC.

Bereiter, C., \& Scardamalia, M. (1993). Surpassing Ourselves: An Inquiry Into the Nature of Expertise. Chicago: Open Court.

Billett, S. (2008). Subjectivity, Learning and Work: Sources and Legacies. Vocations and Learning, 1, 149-171. DOI: 10.1007/s12186-008-9009-y.

Billett, S. (2011). Subjectivity, self, and personal agency in learning through and for work. In M.

Mulloch, L. Cairns, K. Evans, \& B. O'Connor (Eds.). The SAGE Handbook of Workplace Learning (pp. 60-72). Los Angeles, CA: SAGE.

Black, J. P. (2012). Is There a Need for 100\% Verification (Review) of Latent Print Examination Conclusions? Journal of Forensic Identification, 62 (1), 80-100.

Chan, S. (2013). Learning Through Apprenticeship: Belonging to a Workplace, Becoming and Being. Vocations and Learning 6, 367-383. DOI: 10.1007/s12186-013-9100-x.

Cole, M. (2007). Giyoo Hatano's Analysis of Psychological Tools. Human Development, 50, 73-80.

Cole, S. A. (2001). Suspect Identities: A History of Fingerprinting and Criminal Identification. Cambridge, MA: Harvard University Press.

Cole, S. A. (2005). More than Zero: Accounting for Error in Latent Fingerprint Identification. The Journal of Criminal Law \& Criminology, 95 (3), 985-1078.

Collins, H., \& Evans, R. (2002). The Third Wave of Science Studies: Studies of Expertise and Experience. Social Studies of Science, 32 (2), 235-296.

Collins, H., \& Evans, R. (2007). Rethinking Expertise. Chicago, IL: The University of Chicago Press.

D’Andrade, R. (1992). Schemas and motivation. In R. D'Andrade \& C. Strauss (Eds.), Human Motive and Cultural Models (pp. 23-44). Cambridge, MA: Cambridge University Press.

Dror, I., E., \& Charlton, D. (2006). Why Expert Make Errors. Journal of Forensic Identification, 56 (4), 600-616.

Dror, I. E., \& Cole, S. A. (2010). The vision in "blind" justice: Expert perception, judgement, and visual cognition in forensic pattern recognition. Psychonomic Bulletin \& Review, 17 (2), 161-167. DOI: 10.3758/PBR.17.2.161.

Dror, I. E., \& Mnookin, J. (2010). The use of technology in human expert domains: challenges and risks arising from the use of automated fingerprint identification systems in forensic science. Law, Probability and Risk, 9 (1), 47-67.

Engeström, Y. (1987). Learning by Expanding: An Activity-Theoretical Approach to Developmental Research. Helsinki: Orienta-Konsultit.

Eraut, M. (2010). Knowledge, Working Practices, and Learning. In S. Billett (Ed.), Learning Through Practice: Models, Traditions and Approaches (pp. 37-58). Dordrecht: Springer. 
Fleck, L. (1979). Genesis and Development of a Scientific Fact. Chicago, IL: The University of Chicago Press.

Fuller, A., \& Unwin, L. (2004). Young people as teachers and learners in the workplace: challenging the novice-expert dichotomy. International Journal of Training and Development, 8 (1), 32-42.

Fuller, A., \& Unwin, L. (2010). 'Knowledge Workers' as the New Apprentices: The Influence of Organisational Autonomy, Goals and Values on the Nurturing of Expertise. Vocations and Learning, 3, 203-222. DOI: 10.1007/s12186-010-9043-4.

Fuller, A., \& Unwin, L. (2011). Apprenticeship as an evolving model of learning. Journal of Vocational Education \& Training, 63 (3), 261-266. DOI: 10.1080/13636820-2011-602220.

Gartmeier, M., Bauer, J., Gruber, H., \& Heid, H. (2008). Negative Knowledge: Understanding Professional Learning and Expertise. Vocations and Learning, 1, 87-103. DOI: 10.1007/s12186008-9006-1.

Gegenfurtner, A., Siewiorek, A., Lehtinen, E., \& Säljö, R. (2013). Assessing the Quality of Expertise Differences in the Comprehension of Medical Visualizations. Vocations and Learning, 6, 37-54. DOI: $10.1007 / \mathrm{s} 12186-012-9088-7$.

George, A. L., \& Bennett, A. (2005). Case Studies and Theory Development in the Social Sciences. Cambridge: MIT Press.

Goodwin, C. (1994). Professional Vision. American Anthropologist, 96 (3), 606-633.

Gruber, H., Harteis, C., \& Rehrl, M. (2008). Vocational and professional learning: Skill formation between formal and situated learning. In K. U. Mayer \& H. Solga (Eds.). Skill Formation:

Interdisciplinary and cross-natural perspectives (pp. 207-229). Cambridge: Cambridge University Press.

Guile, D. (2011). Apprenticeship as a model of vocational "formation" and "reformation": the use of Foundation Degrees in the aircraft engineering industry. Journal of Vocational Education \& Training, 63 (3), 451-464.

Hakkarainen, K. (2009). A knowledge-practice perspective on technology-mediated learning. Computer-Supported Collaborative Learning 4: 213-231. DOI: 10-1007/s11412-009-9064-X.

Hakkarainen, K., Palonen, T., Paavola, S., \& Lehtinen, E. (2004). Communities of Networked Expertise: Professional and Educational Perspectives. Oxford: Elsevier.

Hatano, G., \& Inagaki, K. (1992). Desituating cognition through the construction of conceptual knowledge. In Context and cognition: Ways of knowing and learning. New York: Harvester.

Kassin, S. M., Dror, I. E., \& Kukucka, J. (2013). The forensic confirmation bias: Problems, perspectives, and proposed solutions. Journal of Applied Research in Memory and Cognition, 2, $42-52$.

Krippendorf, K. (2013). Content Analysis: An Introduction to Its Methodology. Los Angeles, CA: SAGE.

Kruger, J. M., \& Dunning, D. (1999). Unskilled and unaware of it: How difficulties in recognizing one's own incompetence lead to inflated self-assessments. Journal of Personality and Social Psychology, 77 (6), 1121-1134.

Langenburg, G., \& Champod, C. (2011). GYRO System - A Recommended Approach to More Transparent Documentation. Journal of Forensic Identification 61 (4), 373-384. 
Lave, J., \& Wenger, E. (1991). Situated Learning: Legitimate Peripheral Participation. Cambridge, MA: Cambridge University Press.

Leicher, V., Mulder, R. H., \& Bauer, J. (2013). Learning form Errors at Work: A Replication Study in Elder Care Nursing. Vocations and Learning 6, 207-220. DOI: 10.1007/s12186-012-9090-0.

Lin, X., Schwartz, D., \& Bransford, J. (2007). Intercultural Adaptive Expertise: Explicit and Implicit Lessons From Dr. Hatano. Human Development, 50, 65-72.

Mayer, R. E. (1992). Thinking, problem solving, cognition. New York: Freeman.

Mieg, H. A. (2006). Social and sociological factors in the development of expertise. In K. A.

Ericsson, N. Charness, P. Feltovich, \& R. Hoffman (Eds.) The Cambridge Handbook of Expertise and Expert Performance (pp. 743-760). Cambridge, MA: Cambridge University Press.

Mnookin, J. L. (2008). The validity of latent fingerprint identification: confessions of a fingerprinting moderate. Law, Probability \& Risk, 7, 127-141.

Mustonen, V., \& Himberg, K. (2011). A Novel Approach to the Education of Fingerprint Experts. Forensic Science Policy and Management: An International Journal, 2 (1), 28-35.

National Academy of Sciences (NAS). (2009). Executive Summary of the National Academies of Science Reports, Strengthening Forensic Science in the United States; A Path Forward. Forensic Science Policy and Management, 1, 106-122.

National Institute of Justice (NIJ). (2010, 15 January). Education and Training in Forensic Science; A Guide for Forensic Science Laboratories, Educational Institutions, and Students. NIJ Special Report. National Institute of Justice, U.S. Department of Justice. Resource document: http://www.ncjrs.gov/pdffiles1/nij/203099.pdf.

National Institute of Justice (NIJ). (2014, 13, May). The Fingerprint Sourcebook. Resource document: https://www.ncjrs.gov/pdffiles1/nij/225320.pdf

National Institute of Standards and Technology (NIST) \& National Institute of Justice (NIJ). (2014, 13 May). Latent Print Examination and Human Factors: Improving the Practice through a Systems Approach. Resource document. http://www.nij.gov/publications/Pages/all-publications.aspx.

Neisser, U. (1976). Cognition and reality. New York, NJ: W. H. Freeman.

Neuendorf, K.A. (2002). The Content Analysis Guidebook. Los Angeles, CA: Sage.

Novotny, H. (2003). Dilemma of expertise. Democratising expertise and socially robust knowledge. Science and Public Policy, 30 (3), 151-156.

Rittle-Johnson, B., Star, J.R., \& Durkin, K. (2012). Developing procedural flexibility: Are novices prepared to learn from comparing procedures? British Journal of Educational Psychology 82, 436455.

Schön, D. A. (1987). Educating the reflective practitioner: Toward a new design for teaching and learning in the professions. San Francisco, CA: Jossey-Bass.

Styhre, A. (2010). Knowledge work and practices of seeing: Epistemologies of the eye, gaze, and professional vision. Culture and Organisation. 16 (4), 361-376.

The Scientific Working Group on Friction Ridge Analysis, Study and Technology SWGFAST. (2014, 13 May). Standard for the documentation of analysis, comparison, evaluation, and verification (ACE-V), (LATENT). Resource document. http://www.swgfast.org/Documents.html. 
Ulery, B. T., Hicklin, R. A., Buscaglia, J., \& Roberts, M. A. (2012). Repeatability and Reproducibility of Decisions by Latent Fingerprint Examiners. PLoS ONE 7(3): e32800. DOI:10.1371/journal.pone.0032800

Yin, R.K. (2009). Case Study Research. Design and Methods. Applied Social Research Methods Series, Volume 5. Los Angeles, CA: SAGE. 